\title{
Desilication of Highly Acidic Titanyl Chloride Solution for the Production of High- Purity Titania Pigment from a Spent Selective Catalytic Reduction Catalyst
}

\author{
Gyeonghye Moon ${ }^{1,4}$, Yeon-Chul Cho ${ }^{1,2}$, Jin-Young Lee ${ }^{1,3}$ and Jungshin Kang ${ }^{1,3, *}$ \\ ${ }^{1}$ Strategic Minerals Utilization Research Department, Korea Institute of Geoscience and Mineral Resources, \\ 124 Gwahak-ro Yuseong-gu, Daejeon 34132, Korea \\ ${ }^{2}$ Department of Advanced Materials Science and Engineering, Daejin University, 1007 Hoguk-ro, Pocheon-si, Gyeonggi-do 11159, Korea \\ ${ }^{3}$ Department of Resources Recycling, Korea University of Science and Technology, 217 Gajeong-ro Yuseong-gu, Daejeon 34113, Korea \\ ${ }^{4}$ HANNAE For T CO., LTD, 156 Munpyeongdong-ro, 48 Beon-gil, Daedeok-gu, Daejeon 34301, Korea
}

An effective desilication method for a titanyl chloride $\left(\mathrm{TiOCl}_{2}\right)$ solution obtained by dissolving sodium titanate using concentrated hydrochloric acid was investigated in order to increase the purity of titania pigment and the productivity of the process. When the $\mathrm{TiOCl}_{2}$ solution obtained by $\mathrm{HCl}$ leaching was used without desilication, clogging of the filtration system or precipitation of silica occurs. To overcome these disadvantages using a simple and efficient desilication method, the acidity, preservation temperature, and time elapsed after the preservation of $\mathrm{TiOCl}_{2}$ solution were controlled. In the experiments, $\mathrm{TiOCl}_{2}$ solutions produced using $5-7 \mathrm{M} \mathrm{HCl}$ solution were preserved at 274-313 K for 5 days. When the acidity, preservation temperature, and time elapsed after preservation were increased, the removal efficiency of silica increased. The conditions for the concentration of silica below $1 \mathrm{mg} / \mathrm{L}$ and the removal of silica by gelation were determined. When the purified $\mathrm{TiOCl}_{2}$ solution was hydrolyzed at $363 \mathrm{~K}$, titanium dioxide with a purity of $99.6-99.9 \%$ was obtained. Therefore, the results of this study demonstrated a straightforward and effective desilication method for highly acidic $\mathrm{TiOCl}_{2}$ solution. [doi:10.2320/matertrans.M2019045]

(Received February 19, 2019; Accepted April 2, 2019; Published May 25, 2019)

Keywords: selective catalytic reduction (SCR) catalyst, titania pigment, removal of silicon, desilication

\section{Introduction}

Pigments can change the color of a material, for example, by coating. Titania is widely used as a white pigment because it has superior properties such as high opaqueness due to its high refractive index, high brightness, chemical stability, and nontoxicity. ${ }^{1)}$ Owing to its excellent properties, titania is mainly used for coatings, polymers, and paper.

Titania is commercially produced by the sulfate or chloride process. The sulfate process uses low-grade titanium (Ti) ore or titania slag as a feedstock. Digestion of the feedstock is conducted using 80-98\% sulfuric acid $\left(\mathrm{H}_{2} \mathrm{SO}_{4}\right)$ at $443-$ $493 \mathrm{~K}^{2}{ }^{2)}$ As a result, titanium (Ti) and iron (Fe) are transformed to titanyl sulfate $\left(\mathrm{TiOSO}_{4}\right)$ and iron sulfate $\left(\mathrm{FeSO}_{4}\right)$, respectively. $\mathrm{FeSO}_{4}$ is removed from the leach liquor through crystallization by decreasing the temperature to $283-303 \mathrm{~K}^{3,4)}$ Afterward, hydrolysis of the $\mathrm{TiOSO}_{4}$ solution and calcination are carried out to produce the titania pigment. The technological difficulty is not high and the capital cost is low. ${ }^{5)}$ In addition, low-grade Ti ore can be used as feedstock. However, large amounts of $\mathrm{FeSO}_{4}$ waste and acid waste solution are generated. ${ }^{5,6)}$ Furthermore, the quality of titania pigment, such as particle size and impurities, is difficult to control. ${ }^{7}$

In the chloride process, high-grade titanium dioxide $\left(\mathrm{TiO}_{2}\right)$ with a purity of above $95 \%$ is used as feedstock in order to reduce the chlorine loss and prevent the clogging of pipes in carbo-chlorination step. ${ }^{8)}$ The high-grade $\mathrm{TiO}_{2}$ is chlorinated using chlorine $\left(\mathrm{Cl}_{2}\right)$ gas in the presence of carbon at $1273 \mathrm{~K}$ to produce crude titanium tetrachloride $\left(\mathrm{TiCl}_{4}\right){ }^{9)}$ The highpurity $\mathrm{TiCl}_{4}$ obtained by distillation is oxidized to produce high-purity $\mathrm{TiO}_{2}$ under an oxidative atmosphere at 1173$1873 \mathrm{~K}^{2,10}$ ) The chloride process is a semi-continuous

*Corresponding author, E-mail: jskang@kigam.re.kr, jskang@ust.ac.kr process, and the particle size and the impurities affecting the whiteness of the titania pigment are easy to control. ${ }^{7}$ However, the use of $\mathrm{Cl}_{2}$ gas has safety and environmental issues. ${ }^{11)}$ In addition, there are few effective methods for recycling the chloride waste produced, although the amount of chloride waste is not large because of the use of high-grade $\mathrm{TiO}_{2}$.

Owing to the disadvantages of the current titania pigment production processes, several hydrometallurgical processes have been investigated..$^{3,4,12,13)}$ One promising method involves a combination of alkaline roasting of titania slag, water leaching, hydrochloric acid $(\mathrm{HCl})$ leaching, solvent extraction, hydrolysis, and calcination. ${ }^{13)}$ During $\mathrm{HCl}$ leaching in this process, $\mathrm{Ti}$ in sodium titanate, which is obtained after roasting and water leaching, is dissolved and siliceous components in the feed are formed as monosilicic acid $\left(\mathrm{Si}(\mathrm{OH})_{4}\right)$ at initial and particles after polymerization of $\mathrm{Si}(\mathrm{OH})_{4}{ }^{14)}$ In addition, even after filtration, the silica remains in the $\mathrm{TiOCl}_{2}$ solution depending on the conditions of the $\mathrm{HCl}$ leaching and the subsequent treatment of the solution. The remaining silica in the $\mathrm{TiOCl}_{2}$ solution tends to coprecipitate with $\mathrm{TiO}_{2}$ during hydrolysis. ${ }^{14)}$ As a result, the purity of the titania pigment produced is decreased.

The silica in the $\mathrm{TiOCl}_{2}$ solution also decreases the productivity of the process owing to filtration problems by the authors' preliminary study. Figure 1 shows the general theory of polymerization of silica. ${ }^{15)}$ The monosilicic acid condenses and forms cyclic oligomers. ${ }^{14,15)}$ The nanosized particles grown by the polymerization of cyclic oligomers eventually aggregate into 3-dimensional gel networks when the $\mathrm{pH}$ of the solution is low. ${ }^{15,16)}$ In addition, it was reported that the $\mathrm{Si}(\mathrm{OH})_{4}$ in the $2-8 \mathrm{M} \mathrm{HCl}$ solution is polymerized to form primary particles of diameter approximately $5 \mathrm{~nm} .{ }^{17)}$ Then, these primary particles flocculate. During the growth of $\mathrm{Si}(\mathrm{OH})_{4}$ in the acidic solution, silicic acid and/or 


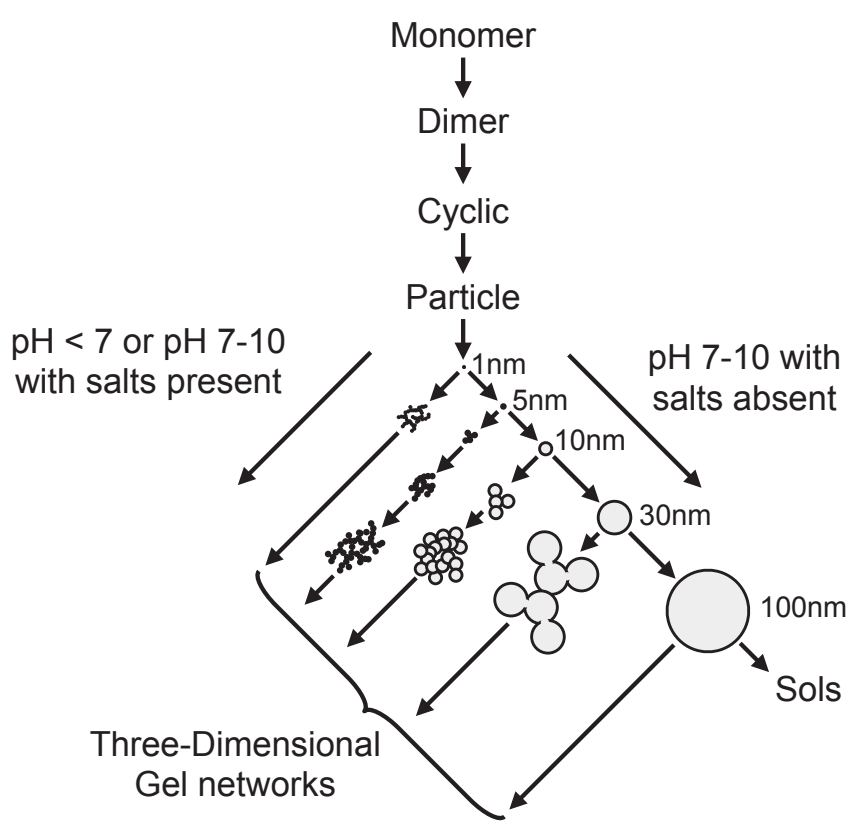

Fig. 1 Polymerization behavior of silica in basic or acid solution. ${ }^{15)}$

nanoprecipitates, with sizes are larger than the filtration limit of $0.20 \mu \mathrm{m}$, block the filtration of the $\mathrm{TiOCl}_{2}$ solution. Therefore, silica in the $\mathrm{TiOCl}_{2}$ solution must be removed before the hydrolysis in order to increase the purity of titania pigment and the productivity of the process.

A few studies have been conducted for understanding the mechanism and the effect of processing variables for the precipitation of silicon ( $\mathrm{Si}$ ) in a highly acidic solution. ${ }^{14,17)}$ Gorrepati reported that polymerization and particle flocculation increased when the concentration of the $\mathrm{HCl}$ solution was increased in $2-8 \mathrm{M} \mathrm{HCl}$ solution. ${ }^{17)}$ In addition, the effects of salts such as $\mathrm{AlCl}_{3}, \mathrm{CaCl}_{2}, \mathrm{MgCl}_{2}$, and $\mathrm{NaCl}$ on the particle formation and growth rate were evaluated. The existence of these salts increased particle formation and growth rate. Lefler also reported the effects of acid concentration, temperature, and selected ionic species on the behavior of $\mathrm{Si}$ in $1-8 \mathrm{M} \mathrm{HCl}$ solution. ${ }^{14)}$ In addition, silica-gel was used as a seed for the adsorption of $\mathrm{Si}$ in the $\mathrm{TiOCl}_{2}$ solution, and the concentration of $\mathrm{Si}$ decreased to $<20 \mathrm{mg} / \mathrm{L}$. Based on these results, it can be summarized that the important variables for the removal of $\mathrm{Si}$ in an acidic solution are acid concentration, temperature, and ionic species in the solution.

Figure 2 shows the process flowchart for the production of high-purity titania pigment from a spent selective catalytic reduction (SCR) catalyst investigated in the Korea Institute of Geoscience and Mineral Resources (KIGAM). The spent SCR catalyst reacts with sodium carbonate $\left(\mathrm{Na}_{2} \mathrm{CO}_{3}\right)$ at $1273 \mathrm{~K}$. In the water leaching, tungsten (W) and vanadium (V) in the soda-melted catalyst dissolve in water, and sodium titanate is obtained as a residue. Afterward, sodium titanate was dissolved using a concentrated $\mathrm{HCl}$ solution to produce the $\mathrm{TiOCl}_{2}$ solution. However, difficulty in the filtration of the $\mathrm{TiOCl}_{2}$ solution or/and the decrease of titania pigment purity obtained after hydrolysis were occurred owing to the remaining silica in the $\mathrm{TiOCl}_{2}$ solution by the author's preliminary study.

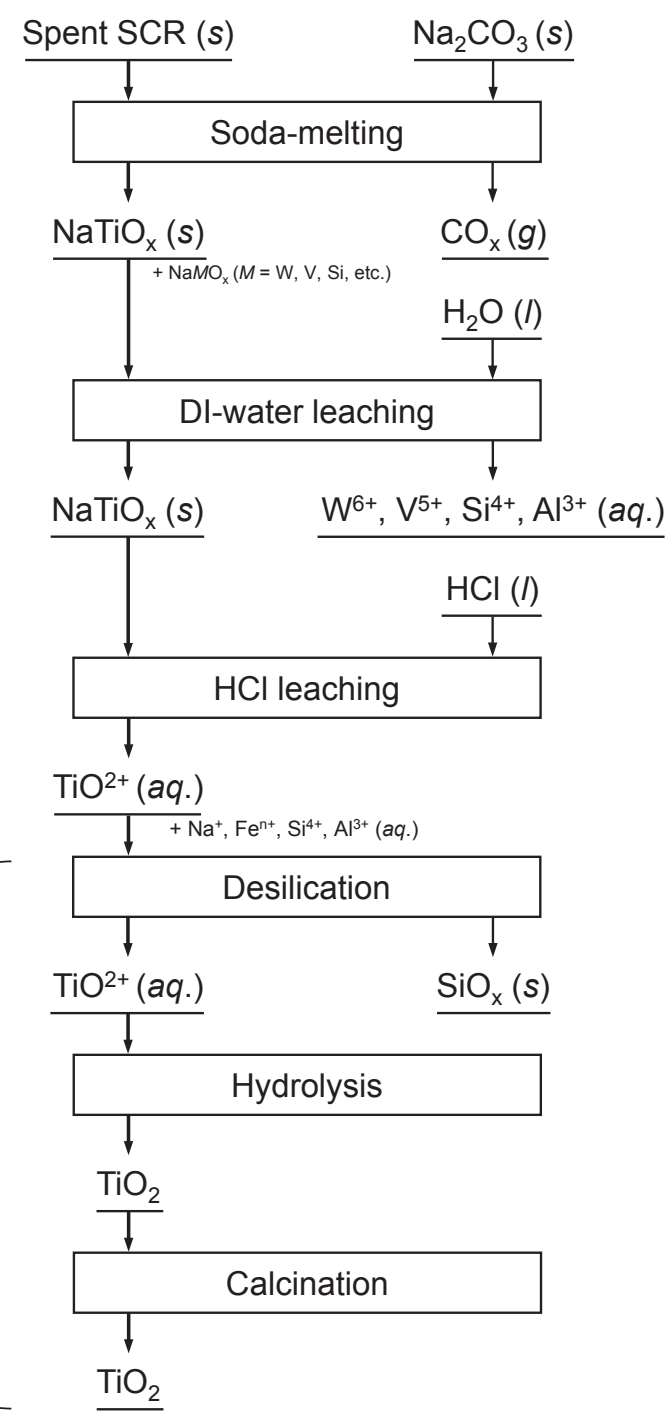

Fig. 2 Flowchart of titania pigment production process, as investigated in the Korea Institute of Geoscience and Mineral Resources.

In this study, the influence of the preservation temperature of the $\mathrm{TiOCl}_{2}$ solution, acidity of the $\mathrm{HCl}$ solution used, and the elapsed time after the preservation of the $\mathrm{TiOCl}_{2}$ solution on the removal of silica was investigated in order to increase the purity of the titania pigment and the productivity of the process. The removal of silica from the $\mathrm{TiOCl}_{2}$ solution obtained by $\mathrm{HCl}$ leaching of the soda-melted spent SCR catalyst has not been reported in the past. In addition, the influence of elapsed time on the silica behavior in the $\mathrm{TiOCl}_{2}$ solution after $\mathrm{HCl}$ leaching has not been investigated. Therefore, the results of this study can be utilized when the practical process employs a combination of alkaline roasting, water leaching, $\mathrm{HCl}$ leaching, hydrolysis, and calcination.

\section{Experimental}

\subsection{Preparation of titanyl chloride solution feed for the removal of silica}

Table 1 lists the composition of the spent SCR catalyst, the residues obtained after soda-melting of the spent catalyst, and the residues obtained after deionized (DI) water leaching. The feedstock of the soda-melting reactions was the spent SCR 
Table 1 Analytical results of the spent SCR catalyst, the residues obtained after soda-melting of the SCR catalyst, and the residues obtained after DI water leaching of the soda-melted SCR catalyst.

\begin{tabular}{lllllllll}
\hline & \multicolumn{8}{l}{ Concentration of element $i, C_{i}$ (mass\%) } \\
\cline { 2 - 9 } & $\mathrm{TiO}_{2}$ & $\mathrm{WO}_{3}$ & $\mathrm{~V}_{2} \mathrm{O}_{5}$ & $\mathrm{Al}_{2} \mathrm{O}_{3}$ & $\mathrm{Fe}_{2} \mathrm{O}_{3}$ & $\mathrm{CaO}$ & $\mathrm{SiO}_{2}$ & $\mathrm{Na}_{2} \mathrm{O}$ \\
\hline Feed (SCR catalyst) & 67.2 & 7.49 & 3.23 & 1.59 & 0.33 & 1.80 & 7.15 & N.A \\
Residues after soda-melting & 34.3 & 4.35 & 1.88 & 1.23 & 0.36 & 0.77 & 4.71 & 39.3 \\
Residues after DI water leaching & 60.4 & 0.06 & 0.03 & 1.68 & 0.63 & 1.41 & 3.36 & 19.0 \\
\hline
\end{tabular}

a: Determined by ICP-OES analysis except $\mathrm{SiO}_{2}$. $\mathrm{SiO}_{2}$ was analyzed by wet analysis (gravimetric analysis). N.A: Not Analyzed.

catalyst installed in a combined heat and power plant in South Korea. The dust inside the catalyst was blown out before pulverization.

The spent SCR catalyst was reacted with $\mathrm{Na}_{2} \mathrm{CO}_{3}$ (purity $=99.0 \%$ ) at $1273 \mathrm{~K}$ for $1 \mathrm{~h}$ using a crucible made of Inconel 600 under atmospheric conditions. The weight ratio of $\mathrm{Na}_{2} \mathrm{CO}_{3}$ to the spent $\mathrm{SCR}$ catalyst was 1.2 , and during the reactions, fused salt was stirred using an impeller, as shown in Fig. 3.

The soda-melted spent SCR catalyst was pulverized and particles in the range of under $75 \mu \mathrm{m}$ were leached using DI water in a polyethylene crucible at room temperature $(297 \pm 2 \mathrm{~K})$ for $1 \mathrm{~h}$ under $20 \%$ solid/liquid $(\mathrm{S} / \mathrm{L})$ ratio $(w / v$, weight of feed $(g) \times 100 /$ volume of solution $(m l))$. The solution was stirred at $500 \mathrm{rpm}$. After the leaching was complete, the leach liquor was settled for $1 \mathrm{~h}$, and filtered (pore size: $0.2 \mu \mathrm{m}$ ). Subsequently, washing of the residue using DI water with stirring at $300 \mathrm{rpm}$ for $10 \mathrm{~min}$, sonication for $20 \mathrm{~min}$., and centrifugation with $4000 \mathrm{rpm}$ for 10 min. (model No.: Combi 408, Hanil Science Industrial Co., Ltd.) were conducted four times. After the final centrifugation was carried out, the residues obtained were dried at $378 \mathrm{~K}$ for $24 \mathrm{~h}$.

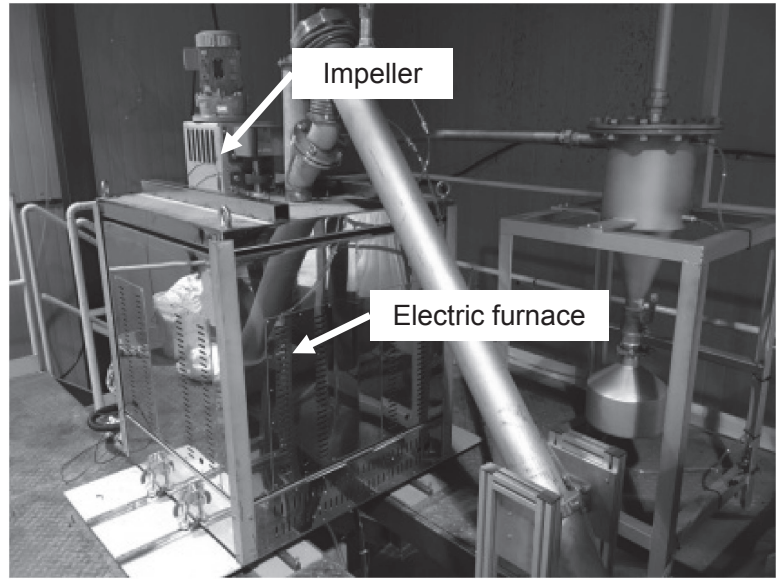

Fig. 3 Photograph of the electric furnace used for the soda-melting of the spent SCR catalyst.

$\mathrm{HCl}$ leaching of the residues obtained after water leaching was conducted using a double-jacketed reactor, as shown in Fig. 4. The residues in a range of under $105 \mu \mathrm{m}$ were dissolved in 5, 6, and $7 \mathrm{M} \mathrm{HCl}$ solutions at $333 \mathrm{~K}$ for $3 \mathrm{~h}$ under $10 \% \mathrm{~S} / \mathrm{L}$ ratio $(w / v)$. The solution was stirred at
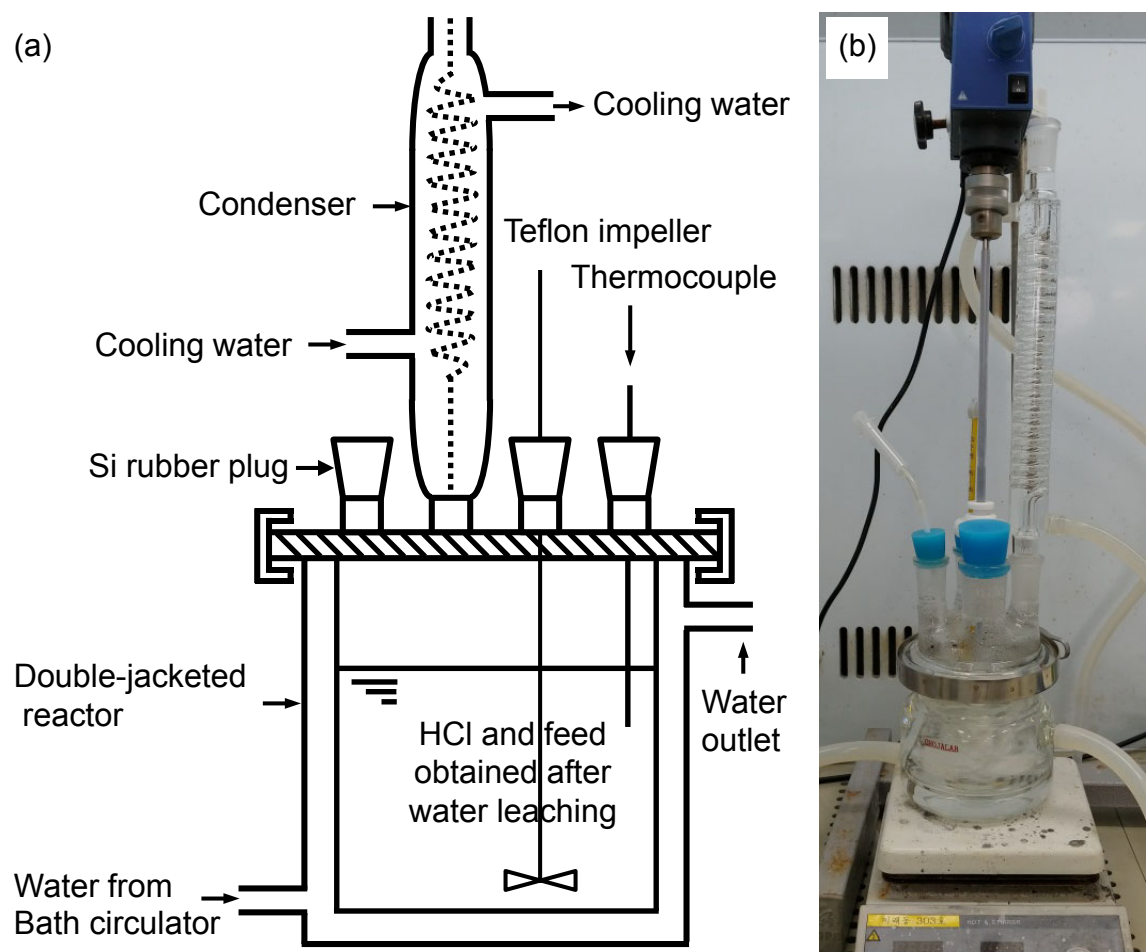

Fig. 4 (a) Schematic and (b) photograph of the experimental apparatus used for HCl leaching. 
$300 \mathrm{rpm}$. The leaching temperature was controlled using a bath circulator (model No.: CW3-10, JEIO TECH Co., Ltd.). To prevent the evaporation of the contents in the reactor, a condenser was used. When the $\mathrm{HCl}$ leaching was complete, the leach liquor was placed in a polyethylene bottle without solid/liquid separation. Subsequently and immediately, the whole liquor was shaken and placed in the three polyethylene bottles uniformly.

\subsection{Removal of silica from the titanyl chloride solution}

Desilication from the $\mathrm{TiOCl}_{2}$ solution prepared by $\mathrm{HCl}$ leaching was conducted at three different temperatures. Each $\mathrm{TiOCl}_{2}$ solution in the polyethylene bottle was placed in a water bath (model No.: BS-21, JEIO TECH Co., Ltd.) set at $313 \mathrm{~K}$, a refrigerator set at $274 \mathrm{~K}$, and a fume hood at room temperature $(297 \pm 2 \mathrm{~K})$ without stirring for 5 days. During the desilication, $2 \mathrm{ml}$ of the solution was taken from the bottles at every $24 \mathrm{~h}$, following which the sample was filtered using a syringe filter unit (pore size: $0.20 \mu \mathrm{m}$, ADVANTEC $^{\circledR}$ ) for the analysis. After 5 days, the $\mathrm{TiOCl}_{2}$ solution in the bottle was centrifuged at $3500 \mathrm{rpm}$ for $15 \mathrm{~min}$ to separate the liquid from the leach liquor, and the liquid was filtered (pore size: $0.20 \mu \mathrm{m})$.

\subsection{Hydrolysis of the purified titanyl chloride solution}

The purified $\mathrm{TiOCl}_{2}$ solution obtained after desilication was hydrolyzed at $363 \mathrm{~K}$ for $3 \mathrm{~h}$ using a double-jacketed reactor. Figure 5 shows the schematic of the experimental apparatus used for hydrolysis. The solution was stirred at $300 \mathrm{rpm}$ using a magnetic bar. The temperature was controlled using a bath circulator, and a condenser was used to prevent the evaporation of the contents in the reactor. After the reactions were completed, the contents of the reactor were filtered (pore size: $0.20 \mu \mathrm{m}$ ). In addition, the residues obtained after the hydrolysis were rinsed thrice using $5 \mathrm{M}$ $\mathrm{HCl}$ solution at room temperature for $5 \mathrm{~min}$, and five times using DI water for $5 \mathrm{~min}$. Afterward, the residues were dried at $378 \mathrm{~K}$. The dried residues were calcined at $973 \mathrm{~K}$ for $1 \mathrm{~h}$ using a muffle furnace.

\subsection{Analysis}

The concentration of the elements in the samples was analyzed with inductively coupled plasma optical emission spectroscopy (ICP-OES: Perkin Elmer, Optima 5300DV). The crystalline phases of the residues obtained were identified by X-ray diffraction (XRD: Rigaku, SmartLab, $\mathrm{Cu}-\mathrm{K} \alpha$ radiation). In addition, the composition and surface of the samples were analyzed using field emission scanning

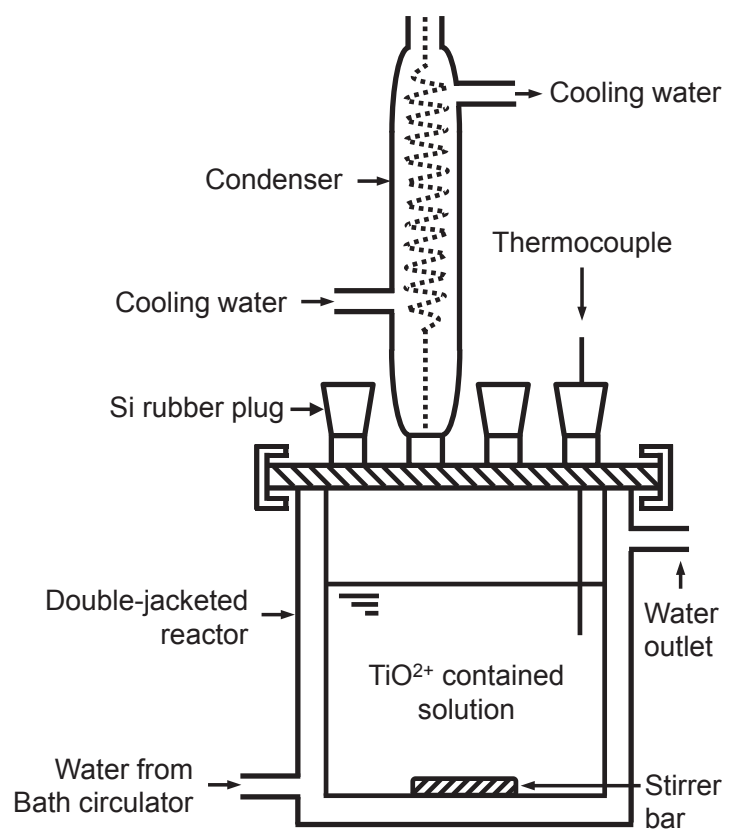

Fig. 5 Schematic of the experimental apparatus used for hydrolysis.

electron microscopy/energy dispersive X-ray spectroscopy (FE-SEM/EDS: Merlin Compact, Carl Zeiss AG/AZTEC, OXFORD INSTRUMENTS).

\section{Results and Discussion}

\subsection{Salts present in the titanyl chloride solution obtained after $\mathrm{HCl}$ leaching}

Table 2 shows the concentration of elements in the $\mathrm{TiOCl}_{2}$ solution feed obtained after $\mathrm{HCl}$ leaching. As shown in Table 2, the major elements dissolved in the $\mathrm{TiOCl}_{2}$ solution are $\mathrm{Ti}$ and sodium $(\mathrm{Na})$ because the residue obtained after water leaching was sodium titanate. Besides $\mathrm{Ti}$ and $\mathrm{Na}$, aluminum (Al), Fe, and calcium (Ca) are also dissolved by the $\mathrm{HCl}$ leaching.

Gorrepati reported that the particle formation and growth rate of silica increased when salts were present in the $\mathrm{HCl}$ solution. ${ }^{17)}$ When $1 \mathrm{M}$ of salt was dissolved in $4 \mathrm{M} \mathrm{HCl}$ solution, the influence on the polymerization of silica according to each type of salt was as follows: $\mathrm{AlCl}_{3}>$ $\mathrm{CaCl}_{2}>\mathrm{MgCl}_{2}>\mathrm{NaCl}$. These results show that ionic strength by salts of the solution affects flocculation rate. ${ }^{17)}$ Unfortunately, the influence of $\mathrm{Ti}$ in the solution on the polymerization of Si was not reported by Gorrepati.

Table 2 Concentration of elements in the titanyl chloride solution feed obtained after $\mathrm{HCl}$ leaching for the removal of silica.

\begin{tabular}{llllllll}
\hline Molarity of $\mathrm{HCl}$ solution used & \multicolumn{9}{l}{ Concentration of element $i, C_{i}(\mathrm{mg} / \mathrm{L})^{\mathrm{a}}$} & \multicolumn{3}{l}{} \\
\cline { 2 - 9 } for $\mathrm{HCl}$ leaching $(\mathrm{mol} / \mathrm{L})$ & $\mathrm{Ti}$ & $\mathrm{W}$ & $\mathrm{V}$ & $\mathrm{Al}$ & $\mathrm{Fe}$ & $\mathrm{Ca}$ & $\mathrm{Na}$ \\
\hline 5 & 28733 & 26 & 13 & 671 & 382 & 291 & 15200 \\
6 & 28733 & 27 & 12 & 664 & 383 & 302 & 14767 \\
7 & 29200 & 28 & 13 & 665 & 363 & 309 & 10433 \\
\hline
\end{tabular}

a: Determined by ICP-OES analysis.

Average value of the concentration of the elements in the titanyl chloride solution contained in three bottles. 
The influence of the acidity of the $\mathrm{HCl}$ solution on the polymerization of silica was also examined. ${ }^{14,17)}$ The flocculation rate of silica was increased by two orders of magnitude when the molarity of $\mathrm{HCl}$ solution was increased from 2 to $8 \mathrm{M} .{ }^{17)}$ These results indicate that the increase of molarity of the $\mathrm{HCl}$ solution can be the dominant factor for the polymerization of silica when the concentration difference of ionic species present among $\mathrm{HCl}$ solutions is not large.

As shown in Table 2, the concentration of $\mathrm{Al}, \mathrm{Fe}$, and $\mathrm{Ca}$ in the three $\mathrm{TiOCl}_{2}$ solutions is significantly lower than that of $\mathrm{Ti}$ and $\mathrm{Na}$. In addition, the concentration difference of $\mathrm{Al}, \mathrm{Fe}, \mathrm{Ca}$, and $\mathrm{Ti}$ among the three $\mathrm{TiOCl}_{2}$ solutions is small. Meanwhile, the concentration of $\mathrm{Na}$ in the $\mathrm{TiOCl}_{2}$ solutions using 5 and $6 \mathrm{M} \mathrm{HCl}$ solutions was higher than that of $\mathrm{Na}$ in the $\mathrm{TiOCl}_{2}$ solution using $7 \mathrm{M} \mathrm{HCl}$ solution by approximately 4300 $4750 \mathrm{mg} / \mathrm{L}$. The solubility of $\mathrm{NaCl}$ in the $\mathrm{HCl}$ solution decreases when the molarity of the $\mathrm{HCl}$ solution is increased. ${ }^{18)}$ As a result, the concentration of $\mathrm{Na}$ in the $\mathrm{TiOCl}_{2}$ solution using $7 \mathrm{M} \mathrm{HCl}$ solution was lower than that in the other two solutions. However, the influence of the concentration difference of $\mathrm{Na}$ in the $\mathrm{TiOCl}_{2}$ solutions on the polymerization of silica is expected to be limited by comparison with the influence of the molarity of $\mathrm{HCl}$ solution on the polymerization of silica. This is because the concentration difference of $\mathrm{HCl}$ solution among three $\mathrm{TiOCl}_{2}$ solutions is significantly larger than the concentration difference of $\mathrm{Na}$ among the $\mathrm{TiOCl}_{2}$ solutions. Therefore, it is expected that the silica in the $\mathrm{TiOCl}_{2}$ solution prepared using $7 \mathrm{M} \mathrm{HCl}$ solution better promotes aggregation than the silica in the $\mathrm{TiOCl}_{2}$ solution prepared using 5 or $6 \mathrm{M} \mathrm{HCl}$ solution.

\subsection{Influence of acidity of $\mathrm{HCl}$ solution, preservation temperature, and time elapsed after preservation for the removal of silica}

Figure 6 shows the influence of preservation temperature and acidity of the $\mathrm{HCl}$ solution used on the concentration change of silica in liquor as days elapsed after the $\mathrm{HCl}$ leaching. As shown in Fig. 6(a), there is no concentration change of silica in the liquor prepared using $5 \mathrm{M} \mathrm{HCl}$ solution when the $\mathrm{TiOCl}_{2}$ solution is preserved at $274-297 \mathrm{~K}$. However, when the $\mathrm{TiOCl}_{2}$ solution is preserved at $313 \mathrm{~K}$, the concentration of silica in the liquor dramatically decreases after 3 days, and the concentration of silica is below $1 \mathrm{mg} / \mathrm{L}$ after 5 days.

In addition, when the $\mathrm{TiOCl}_{2}$ solution prepared using $6 \mathrm{M}$ $\mathrm{HCl}$ solution was used, the concentration of silica did not change when the solution was preserved at $274 \mathrm{~K}$. However, the concentration of silica was below $1 \mathrm{mg} / \mathrm{L}$ after 3 and 2 days had elapsed when the solution was preserved at $297 \mathrm{~K}$ and $313 \mathrm{~K}$, respectively. Furthermore, when the sodium titanate was dissolved using $7 \mathrm{M} \mathrm{HCl}$ solution and the $\mathrm{TiOCl}_{2}$ solution was preserved at 274-313 K, the concentration of silica was below $1 \mathrm{mg} / \mathrm{L}$ after 1 day had elapsed.

These results indicate that the removal efficiency of silica in the $\mathrm{TiOCl}_{2}$ solution prepared using $5-7 \mathrm{M} \mathrm{HCl}$ solution by dissolving sodium titanate with $10 \% \mathrm{~S} / \mathrm{L}$ ratio increased when the preservation temperature was increased in a range of $274-313 \mathrm{~K}$. It is worth noting that the concentration of silica in the $\mathrm{TiOCl}_{2}$ solution below $1 \mathrm{mg} / \mathrm{L}$ implies that the growth of silica has occurred, and that the size of particles,
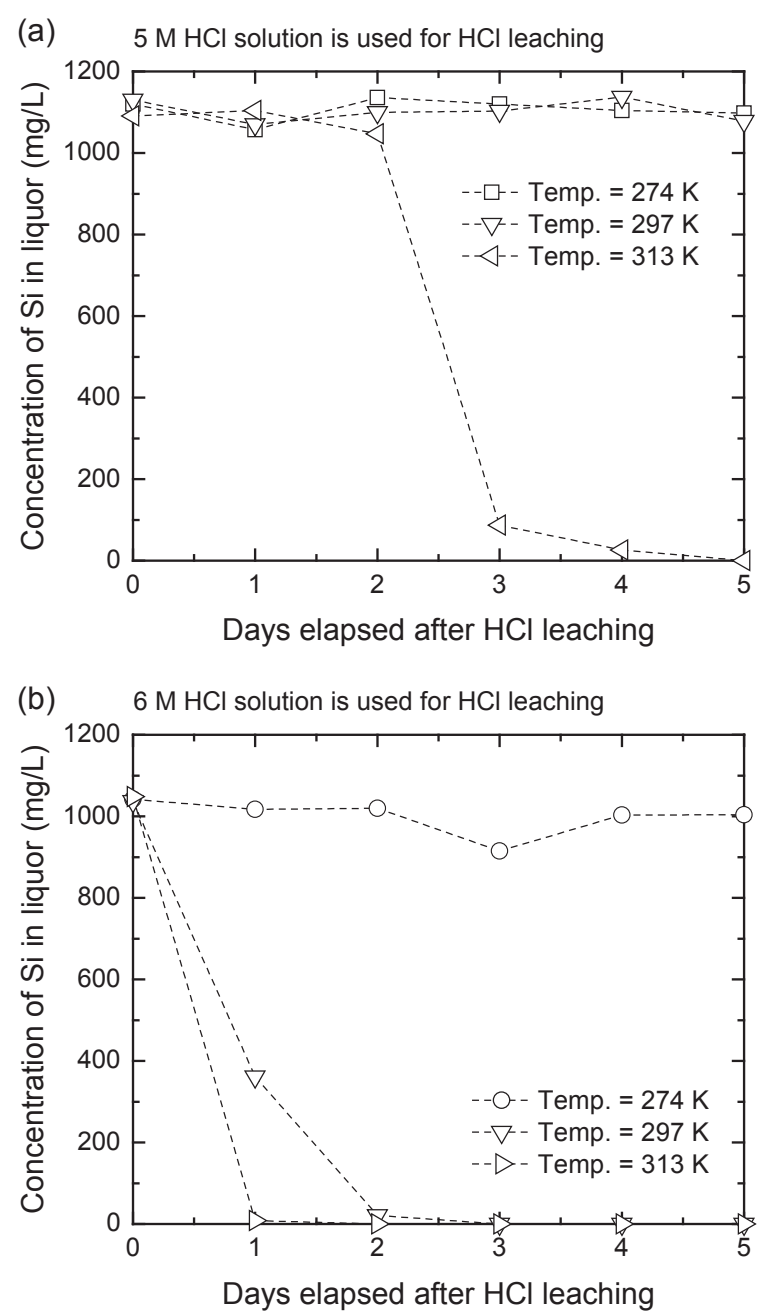

(c) $\quad 7 \mathrm{M} \mathrm{HCl}$ solution is used for $\mathrm{HCl}$ leaching

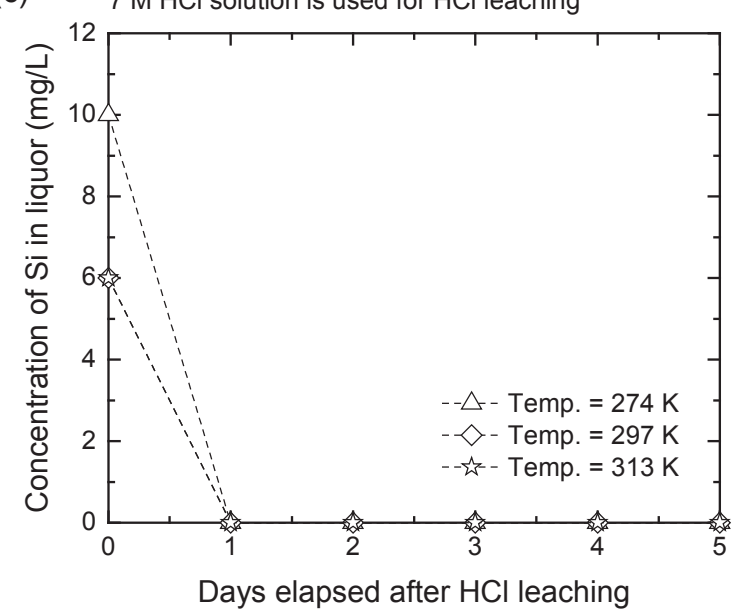

Fig. 6 Influence of the preservation temperature on the concentration change of Si in liquor as days elapsed when (a) $5 \mathrm{M}$, (b) $6 \mathrm{M}$, and (c) $7 \mathrm{M}$ $\mathrm{HCl}$ solution were used.

nanoprecipitates, and/or gel of the generated silica is larger than the pore size of the filter unit $(0.2 \mu \mathrm{m})$.

As shown in Fig. 6, the initial concentration of silica in the $\mathrm{TiOCl}_{2}$ solution prepared using $7 \mathrm{M} \mathrm{HCl}$ solution is much lower than that of silica in the $\mathrm{TiOCl}_{2}$ solution prepared using $5-6 \mathrm{M} \mathrm{HCl}$ solution. These results show that the size of majority of silica in the $\mathrm{TiOCl}_{2}$ solution produced just after the $\mathrm{HCl}$ leaching was larger than the pore size of the filter 
Table 3 Concentration of $\mathrm{Si}(\mathrm{mg} / \mathrm{L})$ in the titanyl chloride solutions when 5 days had elapsed after the $\mathrm{HCl}$ leaching.

\begin{tabular}{llll}
\hline $\begin{array}{l}\text { Molarity of } \mathrm{HCl} \text { solution } \\
\text { used for } \mathrm{HCl} \text { leaching } \\
\text { (mol/L) }\end{array}$ & $\begin{array}{l}\text { Concentration of Si in } \mathrm{HCl} \text { solution of each molarity }(\mathrm{mol} / \mathrm{L}) \\
\text { at preserved temperature }(T) \text { after } 5 \text { days }(\mathrm{mg} / \mathrm{L})^{\mathrm{a}}\end{array}$ \\
\cline { 2 - 4 } & $T=274 \mathrm{~K}$ & $T=297 \mathrm{~K}$ & $T=313 \mathrm{~K}$ \\
\hline 5 & 1098 & 1078 & N.D \\
6 & 1004 & N.D & N.D \\
7 & N.D & N.D & N.D $^{\mathrm{b}}$ \\
\hline
\end{tabular}

a: Concentration of Si was analyzed using ICP-OES, N.D: Not Detected $(<1 \mathrm{ppm})$

b: Gelation of silica was observed after centrifugation.

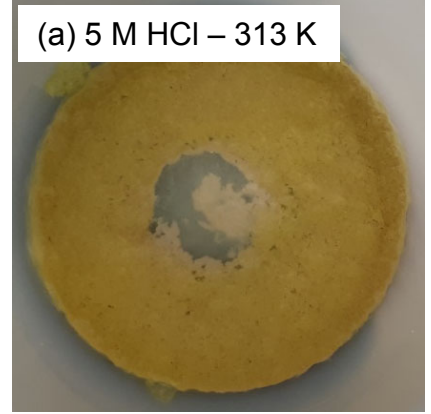

(b) $6 \mathrm{M} \mathrm{HCl}-313 \mathrm{~K}$

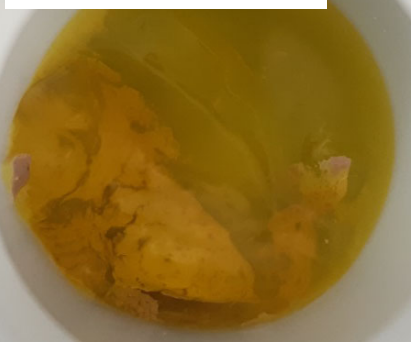

(c) $7 \mathrm{M} \mathrm{HCl}-313 \mathrm{~K}$

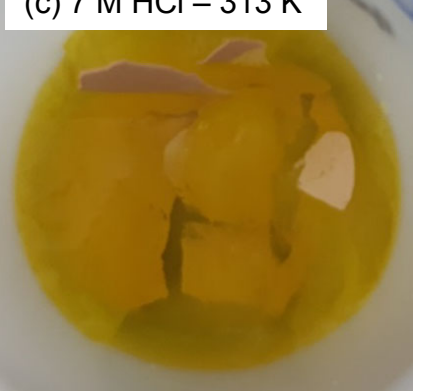

Fig. 7 Residues obtained after centrifugation when the titanyl chloride solutions prepared using (a) $5 \mathrm{M}$, (b) $6 \mathrm{M}$, and (c) $7 \mathrm{M} \mathrm{HCl}$ solution were preserved at $313 \mathrm{~K}$ for 5 days.

unit $(0.2 \mu \mathrm{m})$ when the $\mathrm{HCl}$ leaching of sodium titanate was conducted using $7 \mathrm{M}$ of $\mathrm{HCl}$ solution. From these results, it is also apparent that the growth rate of silica in the $\mathrm{TiOCl}_{2}$ solution prepared using $7 \mathrm{M} \mathrm{HCl}$ solution is higher than that of silica in the $\mathrm{TiOCl}_{2}$ solution prepared using $5-6 \mathrm{M} \mathrm{HCl}$ solution.

Table 3 lists the concentration of silica in the $\mathrm{TiOCl}_{2}$ solutions when 5 days had elapsed after the $\mathrm{HCl}$ leaching. In addition, Fig. 7 shows the residues obtained after centrifugation when the $\mathrm{TiOCl}_{2}$ solution prepared using $5-7 \mathrm{M} \mathrm{HCl}$ solution was preserved at $313 \mathrm{~K}$ for 5 days. As shown in
- NaCl: PDF \#01-070-2509

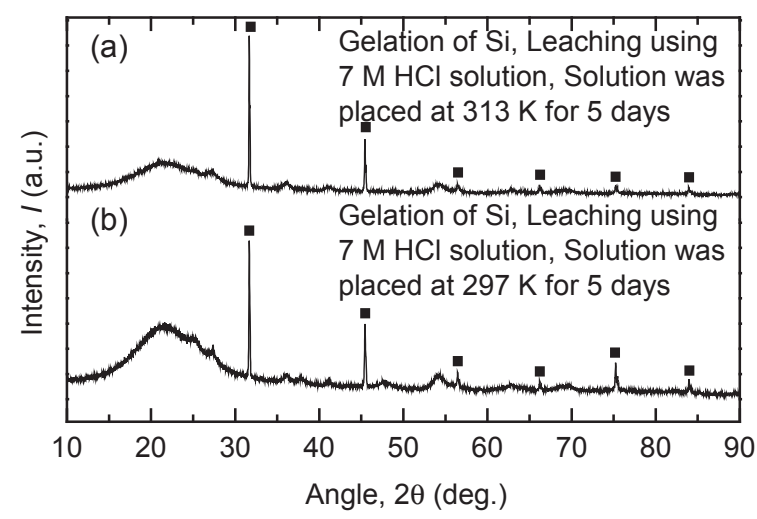

Fig. 8 The results of XRD analysis of the residues obtained when the $7 \mathrm{M}$ $\mathrm{HCl}$ solution was used and titanyl chloride solution after the leaching was preserved at (a) $313 \mathrm{~K}$ and (b) $297 \mathrm{~K}$ for 5 days.

Table 3, the concentration of silica is below $1 \mathrm{mg} / \mathrm{L}$ in the $\mathrm{TiOCl}_{2}$ solution under six conditions depending on the preservation temperature and molarity of the $\mathrm{HCl}$ solution used for the leaching. However, the 3 dimensional gelation of silica, lump of gelation of silica, is observed only under two conditions. As shown in Fig. 7(a), when $5 \mathrm{M} \mathrm{HCl}$ solution is used, 3 dimensional gelation of silica in the $\mathrm{TiOCl}_{2}$ solution is not observed although the concentration of silica in the $\mathrm{TiOCl}_{2}$ solution is below $1 \mathrm{mg} / \mathrm{L}$. However, as shown in Figs. 7(b) and (c), when 6 or $7 \mathrm{M} \mathrm{HCl}$ solution is used, 3 dimensional gelation of silica in the $\mathrm{TiOCl}_{2}$ solution is observed.

When the filtration of the $\mathrm{TiOCl}_{2}$ solution is considered, in addition to the purity of titania pigment, the form of silica grown after the desilication would also be important. When the form of silica after desilication is a particle or a micronsized precipitate, i.e., when the silica has not grown enough to form 3 dimensional silica gel, it would be difficult to filter the $\mathrm{TiOCl}_{2}$ solution because particles or precipitates clog the pores of the filter unit. Therefore, the conditions for the 3-dimensional gelation of silica in the $\mathrm{TiOCl}_{2}$ solution are preferred when the filtration and purity of the pigment are taken into consideration.

Figure 8 shows the results of XRD analysis of the part of silica gel obtained when the $7 \mathrm{M} \mathrm{HCl}$ solution was used and the $\mathrm{TiOCl}_{2}$ solution after the leaching was preserved at $297 \mathrm{~K}$ and $313 \mathrm{~K}$ for 5 days. The silica gel part in the residues was carefully collected, dried at $378 \mathrm{~K}$, and then analyzed. As shown in Fig. 8, only sodium chloride $(\mathrm{NaCl})$ is identified as 

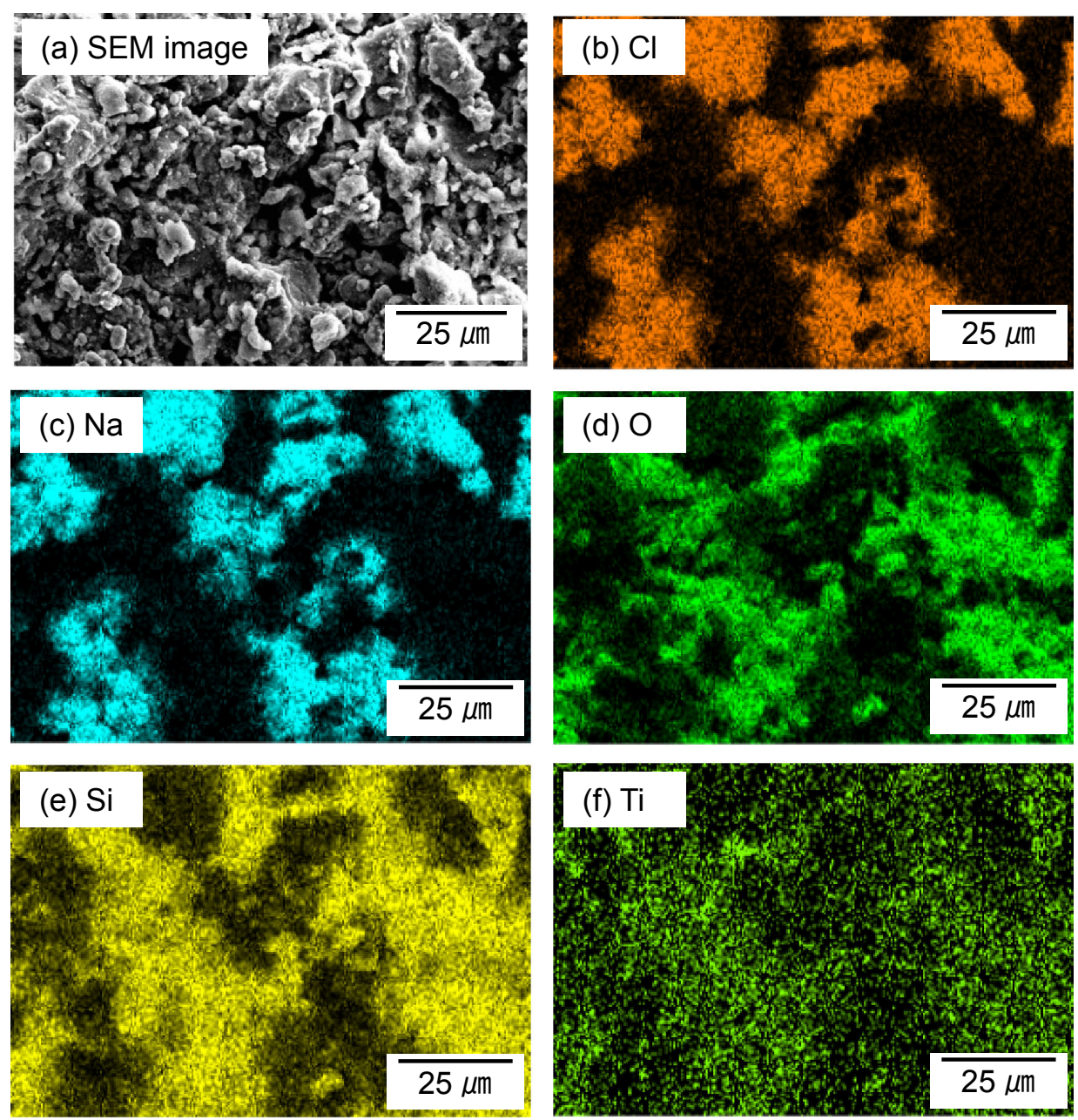

Fig. 9 The results of EDS mapping of the part of silica gel obtained when the $7 \mathrm{M} \mathrm{HCl}$ solution was used and titanyl chloride solution was preserved at $297 \mathrm{~K}$ for 5 days.

a crystalline phase by XRD analysis. Figure 9 shows the results of EDS mapping of the part of silica gel obtained when the $7 \mathrm{M} \mathrm{HCl}$ solution was used and the $\mathrm{TiOCl}_{2}$ solution was preserved at $297 \mathrm{~K}$ for 5 days. These results indicate that silica in the $\mathrm{TiOCl}_{2}$ solution is removed in a form of silicon oxide after the desilication.

\subsection{Hydrolysis of the purified titanyl chloride solution}

Figure 10 shows the recovery efficiency of $\mathrm{Ti}$ and $\mathrm{W}$ from the $\mathrm{TiOCl}_{2}$ solution feed purified via the gelation of silica at $313 \mathrm{~K}$ for 5 days. In addition, Table 4 lists the results of the titania pigment obtained after hydrolysis and calcination.

The recovery efficiency of Ti increased from $14.6 \%$ to $63.5 \%$ when the molarity of $\mathrm{HCl}$ solution used for leaching was decreased from $7 \mathrm{M}$ to $6 \mathrm{M}$. However, it is necessary to increase the recovery efficiency of Ti further. It is expected that the recovery efficiency of $\mathrm{Ti}$ can be increased by decreasing the acidity of the purified $\mathrm{TiOCl}_{2}$ solution or by increasing the temperature for hydrolysis. It is worth noting that almost all $\mathrm{W}$ in the purified $\mathrm{TiOCl}_{2}$ solution was coprecipitated with Ti by hydrolysis. W exists as tungstic acid $\left(\mathrm{H}_{2} \mathrm{WO}_{4}\right)$ in the form of a solid in the concentrated acid. However, it was identified that a small amount of $\mathrm{W}$ was dissolved in the concentrated acid, as shown in

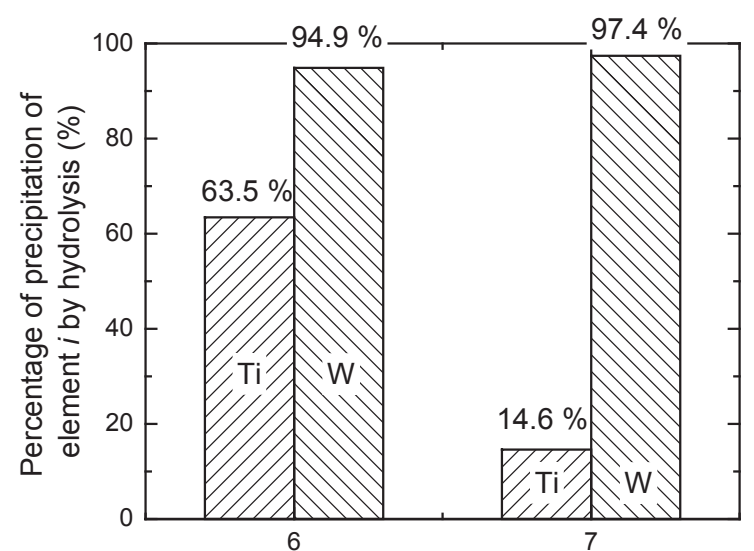

Molarity of $\mathrm{HCl}$ solution used for leaching, $\mathrm{mol} / \mathrm{L}$

Fig. 10 Recovery efficiency of Ti and $\mathrm{W}$ from the titanyl chloride solution feed purified via the gelation of $\mathrm{Si}$ at $313 \mathrm{~K}$ for 5 days.

Table 2, owing to the solubility of $\mathrm{H}_{2} \mathrm{WO}_{4}$ in the $\mathrm{HCl}$ solution. ${ }^{19)}$ Therefore, it is expected that $\mathrm{W}$ dissolved in the purified $\mathrm{TiOCl}_{2}$ solution was precipitated during hydrolysis at $363 \mathrm{~K}$.

After the hydrolysis of the purified $\mathrm{TiOCl}_{2}$ solution, a purity of $99.6-99.9 \%$ of $\mathrm{TiO}_{2}$ was obtained, as shown in 
Table 4 Analytical results of $\mathrm{TiO}_{2}$ obtained after hydrolysis and calcination.

\begin{tabular}{lllllllll}
\hline $\begin{array}{l}\text { Molarity of } \mathrm{HCl} \text { solution } \\
\text { used for } \mathrm{HCl} \text { leaching }(\mathrm{mol} / \mathrm{L})\end{array}$ & \multicolumn{8}{l}{ Concentration of element $i, \mathrm{C}_{i}($ mass \%) } \\
\cline { 2 - 9 } & $\mathrm{Al}_{2} \mathrm{O}_{3}$ & $\mathrm{Na}_{2} \mathrm{O}$ & $\mathrm{Fe}_{2} \mathrm{O}_{3}$ & $\mathrm{CaO}$ & $\mathrm{WO}_{3}$ & $\mathrm{~V}_{2} \mathrm{O}_{5}$ & $\mathrm{SiO}_{2}$ & $\mathrm{TiO}_{2}{ }^{\mathrm{b}}$ \\
\hline 6 & $\mathrm{~N} . \mathrm{D}$ & N.D & N.D & N.D & 0.06 & N.D & N.D & 99.94 \\
7 & N.D & N.D & N.D & N.D & 0.43 & N.D & N.D & 99.57 \\
\hline
\end{tabular}

a: Concentration was determined using ICP-OES analysis, N.D: Not Detected $(<0.010$ mass $\%)$

b: Concentration of $\mathrm{TiO}_{2}$ was calculated as follows: $\mathrm{TiO}_{2}$ purity $=100-($ conc. of oxides of $\mathrm{Al}, \mathrm{Na}, \mathrm{Fe}, \mathrm{Ca}, \mathrm{W}, \mathrm{V}$, and $\mathrm{Si}$ )

Table 4. The only impurity detected was W. The purity of titania pigment obtained in this study satisfied the international standard for titanium dioxide pigments for paints (ISO 591-1:2000(E)), which requires $97-98 \%$ of $\mathrm{TiO}_{2}$. However, development of a method for the further removal of $\mathrm{W}$ from the purified $\mathrm{TiOCl}_{2}$ solution is necessary.

Figure 11 shows the results of the XRD analysis of the titania pigment calcined at $973 \mathrm{~K}$ for $1 \mathrm{~h}$. As shown in Fig. 11, a rutile type of titania pigment is obtained. Figure 12 shows the particles of the titania pigment produced after calcination; micron-sized titania pigment is obtained.

\section{Conclusions}

The removal of silica in the highly acidic $\mathrm{TiOCl}_{2}$ solution obtained by $\mathrm{HCl}$ leaching of the sodium titanate produced using spent SCR catalyst was investigated for increasing the purity of the titania pigment product and the productivity of the process by resolving the filtration problem. The influence of acidity, preservation temperature, and time elapsed after preservation on the removal efficiency of silica in the $\mathrm{TiOCl}_{2}$

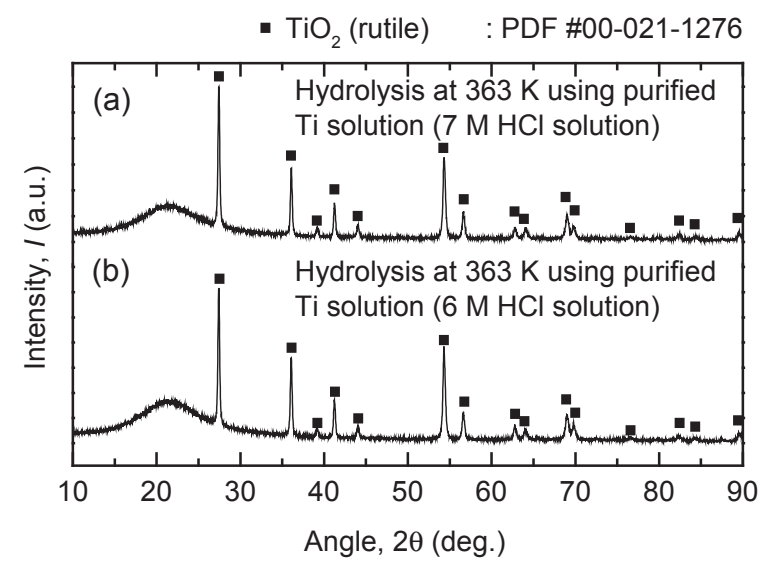

Fig. 11 The results of XRD analysis of the titania pigment calcined at $973 \mathrm{~K}$ for $1 \mathrm{~h}$ using particles obtained by the hydrolysis of purified titanyl chloride solution prepared by (a) $7 \mathrm{M}$ and (b) $6 \mathrm{M} \mathrm{HCl}$ solution.

solution produced by dissolving sodium titanate using 5-7 M $\mathrm{HCl}$ solutions under $10 \% \mathrm{~S} / \mathrm{L}$ ratio $(w / v)$ was evaluated. In addition, the titania pigment obtained by the hydrolysis of the
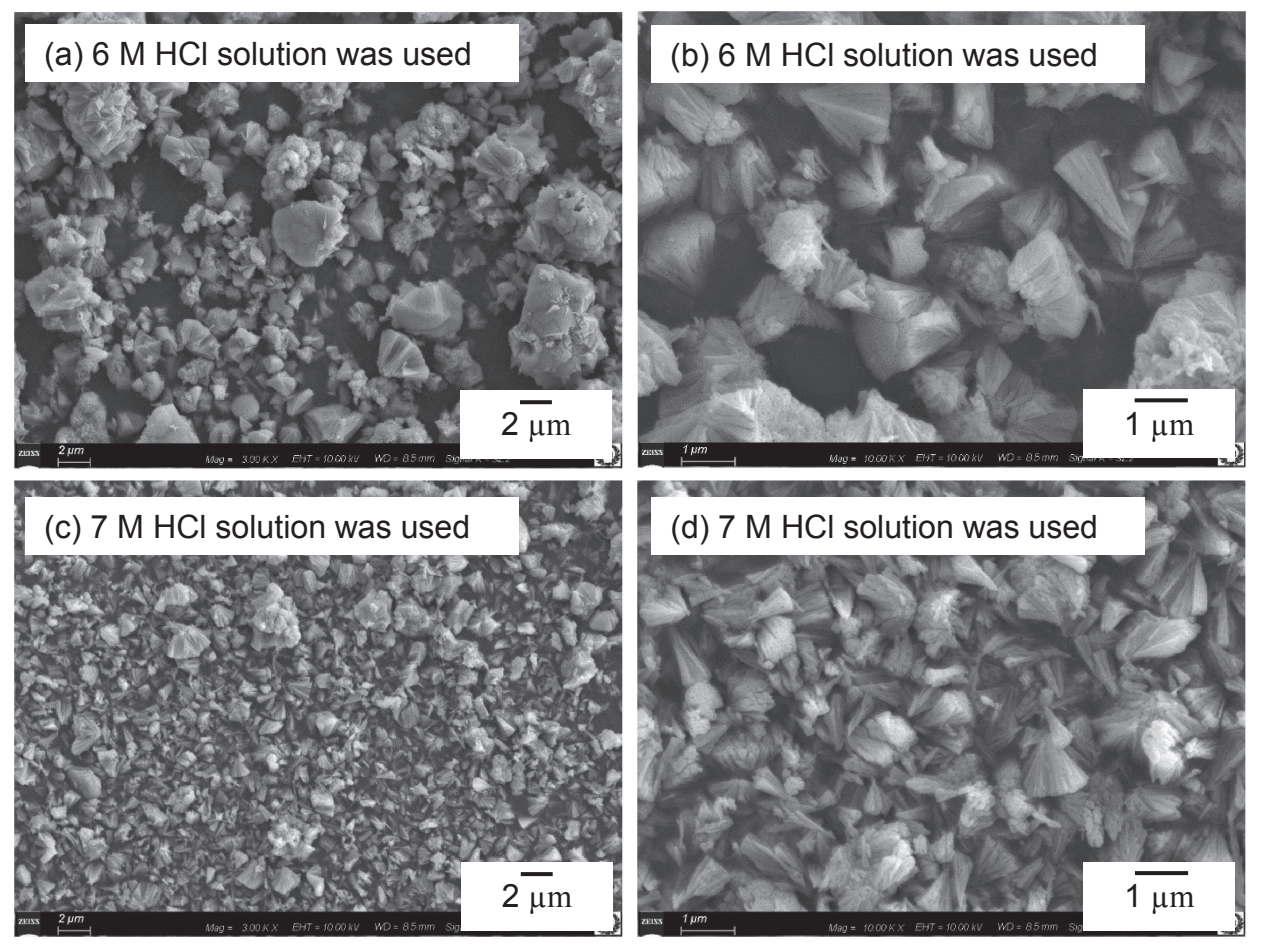

Fig. 12 Images of titania pigment produced after calcination using particles obtained by hydrolysis of the purified titanyl chloride solution prepared by (a) (b) $6 \mathrm{M}$ and (c) (d) $7 \mathrm{M} \mathrm{HCl}$ solution. 
purified $\mathrm{TiOCl}_{2}$ solution was also evaluated. Based on the results, the following conclusions can be drawn:

(1) When the $\mathrm{TiOCl}_{2}$ solution prepared using $5 \mathrm{M} \mathrm{HCl}$ solution was preserved at $313 \mathrm{~K}$, the concentration of silica was below $1 \mathrm{mg} / \mathrm{L}$ after 5 days had elapsed.

(2) When the $\mathrm{TiOCl}_{2}$ solution prepared using $6 \mathrm{M} \mathrm{HCl}$ solution was preserved at $297 \mathrm{~K}$ and $313 \mathrm{~K}$, the concentration of silica was below $1 \mathrm{mg} / \mathrm{L}$ after 3 and 2 days had elapsed, respectively.

(3) When the $\mathrm{TiOCl}_{2}$ solution prepared using $7 \mathrm{M} \mathrm{HCl}$ solution was preserved at $274-313 \mathrm{~K}$, the concentration of silica was below $1 \mathrm{mg} / \mathrm{L}$ after 1 day had elapsed.

(4) $\mathrm{Si}$ was removed as silicon oxide, and when the $\mathrm{TiOCl}_{2}$ solution prepared using $6-7 \mathrm{M} \mathrm{HCl}$ solution was preserved at $313 \mathrm{~K}, 3$ dimensional gelation of silica occurred.

(5) When the $\mathrm{TiOCl}_{2}$ solution prepared using 6-7 M HCl solution was hydrolyzed at $363 \mathrm{~K}$ after the desilication, micron-sized $\mathrm{TiO}_{2}$ with a purity of $99.6-99.9 \%$ was obtained.

\section{Acknowledgments}

The authors are grateful to Dr. In-Hyeok Choi, Dr. TaeHyuk Lee, Mr. Hee-Nam Kang and Ms. Jieun A. Ahn for their technical support and discussion throughout this study. The authors are also grateful to all the members of the Geoanalysis Department of KIGAM for their technical assistance. This research was supported by the R\&D center for valuable recycling (Global-Top Environmental Technology Development Program) funded by the Korean Ministry of the Environment in Korea (Project No.: GT-11-C-01230-0) and the Korea Evaluation Institute of Industrial
Technology funded by the Korean Ministry of Industry in Korea (Project No.: 20000970, 18-9805).

\section{REFERENCES}

1) J.H. Braun, A. Baidins and R.E. Marganski: Prog. Org. Coat. 20 (1992) 105-138.

2) F. Habashi: Handbook of Extractive Metallurgy, (VCH Verlagsgesellschaft mbH, Germany, 1997).

3) E.G. Roche, A.D. Stuart and E.P. Grazier: US 7485269 B2 (2009a).

4) E.G. Roche, A.D. Stuart, E.P. Grazier and H. Liu: US 7485268 B2 (2009b).

5) W. Zhang, Z. Zhu and C.Y. Cheng: Hydrometallurgy 108 (2011) 177188.

6) K.K. Sahu, T.C. Alex, D. Mishra and A. Agrawal: Waste Manag. Res. 24 (2006) 74-79.

7) M. Matsunaga: J. Japan Soc. Colour Mater. 54 (1981) 680-689.

8) J. Kang and T.H. Okabe: Mater. Trans. 55 (2014) 591-598.

9) N. Nakamura: Molten Salts 56 (2013) 121-124.

10) R.A. Gonzalez: US 5562764 (1996).

11) J. Kang and T.H. Okabe: Metall. Mater. Trans. B 44 (2013) 516527.

12) V. I. Lakshmanan, R. Sridhar, Harris, G. Bryn and G. Puvvada: US 7803336 B2 (2010).

13) S. Middlemas, Z.Z. Fang and P. Fan: Hydrometallurgy 131-132 (2013) 107-113.

14) H. Lefler, Y. Zhang, Z.Z. Fang, M. Free and Z. Huang: Hydrometallurgy 173 (2017) 218-223.

15) R.K. Iler: The Chemistry of Silica, (A Wiley-Interscience Publication, United States of America, 1979).

16) N.A. Milne, T. O’Reilly, P. Sanciolo, E. Ostarcevic, M. Beighton, K. Taylor, M. Mullett, A.J. Tarquin and S.R. Gray: Water Res. 65 (2014) 107-133.

17) E.A. Gorrepati, P. Wongthahan, S. Raha and H.S. Fogler: Langmuir 26 (2010) 10467-10474.

18) R.W. Potter and M.A. Clynne: J. Chem. Eng. Data 25 (1980) 50-51.

19) L. Honggui, Y. Jiangao and L. Kun: Tungsten Metallurgy, (Central South University Press, China, 2010). 